\title{
Hospitalists and their roles in the COVID-2019 pandemic in the United States and beyond
}

\author{
Catherine Washburn, Venkat Gundareddy, and Flora Kisuule* \\ Division of Hospital Medicine, Johns Hopkins Bayview Medical Center, Johns Hopkins School of Medicine, Baltimore, MD, USA
}

\section{Introduction}

In 2019, the virus known as severe acute respiratory syndrome coronavirus 2 (SARS-CoV-2) spread across the world causing coronavirus disease 2019 (COVID19). On March 11, 2020, the World Health Organization (WHO) declared COVID-19 a pandemic ${ }^{1}$. As hospitalizations increased, institutions around the world developed processes to address this need. Hospitalists were at the forefront of caring for COVID-19 patients, serving in multiple roles including: clinicians, operational disaster planners, researchers, innovators of COVID-19 care, and leaders of alternate care sites (ACS) for COVID-19 patients. We performed a literature review to understand the impact of hospitalists during the COVID-19 pandemic in the United States and abroad.

\section{Background on hospital medicine}

Hospital medicine is the fastest growing specialty in the United States with estimates of over $50,000^{2}$ practitioners. Focusing on provision of comprehensive medical care to hospitalized patients, physicians who specialize in hospital medicine are known as hospitalists. Because they are close to the bedside, hospitalists expertly diagnose unusual conditions, anticipate problems, coordinate with consultants, and quickly recognize clinical crises. In addition, hospitalists teach, do research, and lead within their specialty and in hospital administration. Hospitalists promote patient safety and improve the efficiency and performance of hospitals and health systems.

An interesting aspect of the rapid expansion of hospital medicine is the growth of the field beyond the United States, shown by 20,000 North American Society of Hospital Medicine (SHM) members and an additional 126 international hospitalist members ${ }^{3}$. Although health care delivery, regulations and cultural norms across the world differ, there are striking similarities in the roles that hospitalists have played across the world in the fight against the COVID-19 pandemic.

\section{Hospitalists as front-line clinicians}

More than 122 million people have been infected with COVID-19 worldwide and 2.7 million have died ${ }^{4}$. The United States leads the world in the number of cases, nearly 30 million, and the number of deaths, over $500,000^{5}$. An estimated $20 \%$ of COVID-19 patients have severe disease requiring hospitalization and $6-17 \%$ of those require intensive care ${ }^{6}$. Dedicated units were developed in the United States and worldwide to centralize patient care and facilitate infection control. Strained health-care systems used creative staffing models to ensure adequate provider coverage. Hospitalists have provided direct patient care and anchored teams of redeployed clinicians unaccustomed
Correspondence:

*Flora Kisuule

E-mail: Fkisuul1 @jhmi.edu
Available online: $05-10-2021$
Span J Med. 2021;1(3):132-135

www.spanishjmed.com 2696-5631 / @ 2021 Sociedad Española de Medicina Interna. Published by Permanyer. This is an open access article under the CC BY-NC-ND license (http://creativecommons.org/licenses/by-nc-nd/4.0/). 
to hospital-based practice, mobilized in the face of surging COVID-19 numbers ${ }^{7,8}$. Hospitalists provided overnight coverage, trainee supervision, staffing of rapid response and cardiac arrest teams ${ }^{8}$, and management of general medicine and intensive care patients, partnering with intensivists ${ }^{9}$. Quarantined hospitalists continued working from home, covering triage calls ${ }^{10}$ or cross covering hospitalized patients, relieving the burden of hospitalists on site.

Spain ranks in the top ten countries in raw numbers of COVID-19 cases, 3.21 million, with approximately 73,000 deaths $^{5}$. Hospital Clinico San Carolos, a 750bed facility in Madrid, has 4 hospitalists who co-manage surgery patients. During the pandemic's first wave, this hospital doubled its bed capacity to 1400 . Teams of medical and surgical specialists formed to care for COVID-19 patients. One hospitalist led a team of 16 doctors caring for 76-80 patients. In subsequent waves, these hospitalists engaged in direct patient care (Dr. Arantza Alvarez de Arcaya, Coordinadora de Medicine Hospitalista, personal communication, March 21, 2021).

\section{Hospitalists in operational disaster planning}

Hospital disaster response plans traditionally center on emergency departments. However, the COVID-19 pandemic has placed hospitalists front and center in hospital preparedness. They have around-the-clock in-house presence and expertise in admission triage, medical co-management, and coordination of complex medical care. Hospitalists are thus uniquely qualified to lead disaster preparedness efforts and have orchestrated complex and dynamic clinical operational plans in response to this pandemic ${ }^{7,11}$. Specifically, hospitalists have helped create biocontainment units for patients infected with SARS-CoV-2, developed staffing models to cover higher and fluctuating patient volumes, and developed frameworks for hospital operations in anticipation of a massive influx of acutely ill, medically complex, and highly contagious patients?

\section{Hospitalists developing and providing leadership at alternate care sites}

Models of COVID-19 peaks predicted hospital bed shortages worldwide and indeed many of these shortages were realized. Anticipating bed needs, governments around the world rushed into historically unprecedented interventions including the development of alternate care sites (ACSs). Convention halls, parking garages, abandoned industrial warehouses, and pavilions became overflow hospitals for COVID19 patients in the United States, Canada, and Spain. Vancouver, in Canadian British Columbia, is home to a field hospital with 270 beds in its convention center, staffed in part, by hospitalists ${ }^{12}$. One of the longest running ACSs in the United States is the 250 bed Baltimore Convention Center Field Hospital (BCCFH), where the Chief Medical Officer (CMO), the associate $\mathrm{CMO}$, and multiple medical directors are hospitalists ${ }^{13}$. These hospitalist leaders developed admission criteria and care processes to provide medical care on site until patients are ready for discharge ${ }^{12}$, and BCCFH also offers COVID-19 testing, monoclonal antibody infusion, and vaccine administration. To date, the BCCFH has seen 1100 inpatients, administered 1500 antibody infusions, 34,000 vaccines, and 96,000 COVID-19 tests (Dr. Mindy Kantsiper, hospitalist and $\mathrm{CMO}, \mathrm{BCCFH}$, personal communication).

\section{Hospitalists Innovating in COVID-19 care}

The COVID-19 pandemic has brought opportunities for quality and patient safety initiatives. Hospitalists have led innovations in Point of Care Ultrasound (POCUS), tele-health, and extension of the virtual hospital model.

\section{POCUS}

Many hospitalists incorporate POCUS into their daily practice because it enhances their physical exam ${ }^{14}$. Recently clinicians have used POCUS imaging of the heart and lungs to support the diagnosis and progression of care of patients with COVID-19. The diagnostic accuracy of lung ultrasound has been reported to be similar to chest CT scans in patients with respiratory complaints $^{15}$. Mathews et al. report that the American Society of Echocardiography has recommended the use of cardiac POCUS by frontline providers for detection or characterization of preexisting cardiovascular disease and early identification of worsening cardiac function associated with COVID-1915,16. Myriad cardiac complications have been described in this disease: acute coronary syndrome, myocarditis, arrhythmias, cardiomyopathy, and heart failure. POCUS can detect lower extremity deep vein thrombosis associated with the pro-inflammatory and hypercoagulable state of COVID-19 and facilitate placement of central and peripheral venous catheters. 


\section{Telemedicine}

Telemedicine is not new but is increasingly recognized as an important tool in clinical care delivery ${ }^{17-19}$. Pre-pandemic telemedicine focused on mental health, primary care, and asynchronous store-and-forward applications $^{20}$. During the COVID-19 pandemic, telehealth has been used both to progress the care of hospitalized patients ${ }^{20}$ and to avoid transfers from rural hospitals to overwhelmed tertiary and quaternary care hospitals.

As states declared emergency status, financial and regulatory roadblocks to telehealth loosened, including limited reimbursement, HIPAA compliance, and interstate licensing restrictions. Guiterrez et al. adapted their lowa tele-hospitalist program to link their tertiary care center with understaffed rural hospitals and to provide hospital-to-home telehealth for recently discharged patients ${ }^{20}$. In New York, Becker et al. created a tele-hospitalist service for COVID-19 patients on the general medical ward. They write: "these hospitalists helped to coordinate care standardization, supervised clinical best practices, and communicated effectively with patient logistics and inpatient care teams. The combination of these tasks resulted in load balancing for our bedside internal medicine hospitalist teams."

Many hospitalist groups used inpatient tele-medicine to facilitate social distancing and limit provider exposure to infectious patients. Hospitalists took a history using HIPAA-compliant technology through the electronic health record, online platforms, iPads, or smartphones $^{8}$. Hospitalists used technology to maintain their practice of connecting with their patients many times daily to address concerns.

\section{Hospital at home}

As SARS-CoV-2 spread, health systems became overwhelmed by COVID-19 cases. Staffing, supplies of equipment, and hospital and intensive care unit beds were insufficient, and quality of care suffered ${ }^{21}$. In response, Sitammagari et al. developed and deployed a virtual hospital program. This model provided proactive home monitoring and hospital level care through virtual observation and acute care units at home for eligible patients with COVID-19. At Atrium Health, the hospital at home extends the hospital medicine division. Hospitalists partner with nurses to provide intravenous fluids, antibiotics, respiratory treatments, and supplemental oxygen in this virtual acute care unit ${ }^{21}$.

\section{Hospitalists contributing to scholarship}

When the WHO declared COVID-19 a pandemic, little was known about the virus and even less about its treatment. Front line hospitalists quickly turned their observations and experience into research that has contributed to the fund of knowledge in this novel disease. From pooled testing ${ }^{22}$, ward adaptions ${ }^{23}$, mortality ${ }^{24}$, and outcomes of floor level COVID19 cases $^{25}$, to glucocorticoid treatment ${ }^{26,27}$ and non-invasive ventilation ${ }^{28}$, hospitalists have innovated and published their findings. Hospitalists have also trained redeployed clinicians and developed the needed educational materials, including clinical guidelines, Electronic Health Record primers, and workflow tips.

\section{Conclusion}

Hospitalists add immense value to a hospital system in the areas of patient safety and quality, cost effective care, access and availability, patient satisfaction, leadership, and education ${ }^{29}$. Their $24 / 7$ presence in the hospital means that they provide undivided attention to patient care. Hospitalists, therefore, have had a major role in the COVID-19 pandemic as front-line clinicians, leaders in developing operations to expand hospital physical and human resource capacity, and innovators at the leading edge of the development and evolution of care. This hospitalist impact is profound in the United States and beyond.

\section{References}

1. World Health Organization Director-general, Opening Remarks at the Media Briefing on COVID-19. Available from: https://www.who.int/director-general/speeches/detail/who-director-general-s-opening-remarks-atthe-media-briefing-on-covid-19---11-march-2020. [Last accessed on 2021 Mar 06]

2. Wachter RM, Goldman L. Zero to $50,000-$ The $20^{\text {th }}$ anniversary of the hospitalist. N Engl J Med. 2016;375:1009-11.

3. Kisuule F, Howell E. Hospital medicine beyond the United States. Int J Gen Med. 2018;11:65-71.

4. World Health Organization. Coronavirus Disease (COVID-19) Dashboard Geneva: World Health Organization; 2021 Available from: https://www. covid19.who.int. [Last accessed on 2021 Mar 21].

5. CDC Data Tracker. Available from: https://www.covid.cdc.gov/covid-data-tracker/\#global-counts-rates. [Last accessed on 2021 Mar 21].

6. Wu Z, McGoogan JM. Characteristics of and important lessons from the coronavirus disease 2019 (COVID-19) outbreak in China: summary of a report of 72,314 cases from the Chinese center for disease control and prevention. JAMA. 2020;323:1239-42.

7. Bowden K, Burnham E, Keniston A, Levin D, Limes J, Persoff J, et al. Harnessing the power of hospitalists in operational disaster planning: COVID-19. J Gen Intern Med. 2020;35:2732-7.

8. Jacobs L, Korcak J, Zetkulic M. Physician workforce response to the COVID-19 pandemic at an academic medical center. Disaster Med Public Health Prep. 2020;Oct 12:1-4.

9. Cutler T, Eisenberg N, Evans A. Inpatient management of COVID-19 pneumonia: a practical approach from the hospitalist perspective. J Gen Intern Med. 2020;Jun 4:1-4.

10. Yetmar Z, Issa M, Munawar S, Burton MC, Pureza V, Sohail MR, et al. Inpatient care of patients with COVID-19: a guide for hospitalists. Am J Med. 2020;133:1019-24. 
11. Persoff J, Ornoff D, Little C. The role of hospital medicine in emergency preparedness: a framework for hospitalist leadership in disaster preparedness, response, and recovery. J Hosp Med. 2018;13:713-8.

12. Howelett K, Ontario BC. Quebec Begin Building Makeshift Hospitals in Preparation for Rise in COVID-19 Patients. Available from: https://www. theglobeandmail.com/canada/article-ontario-bc-quebec-begin-building-makeshift-hospitals-in. [Last accessed on 2021 Mar 03].

13. Chaudhary M, Howell E, Ficke J, Loffredo A, Wortman L, Benton GM et al. Caring for patients at a COVID-19 field hospital. J Hosp Med. 2021;16:117-9.

14. Soni N, Schnobrich D, Mathews B, Tierney DM, Jensen TP, Dancel R, et al. Point-of-care ultrasound for hospitalists: a position statement of the society of hospital medicine. J Hosp Med. 2019;14:E1-6.

15. Mathews B, Koenig S, Kurian L, Galen B, Mints G, Liu G, et al. Clinical progress note: point-of-care ultrasound applications in COVID-19. J Hosp Med. 2020;15:353-5.

16. Johri AM, Galen B, Krikpatrick J, Lanspa M, Mulvagh S, Thamman R ASE statement on point-of-care ultrasound (POCUS) during the 2019 novel coronoavirus pandemic. J Am Soc Echocardiogr. 2020;33: 670-3.

17. Becker C, Lorman L, Gallapudi L, Nevins B, Scurlock C. Rapid implementation and adaptation of a telehospitalist service to coordinate and optimize care for COVID-19 patients. Telemed J E Health. 2021;27: 388-96.

18. Moeckli J, Gutierrez J, Kaboli P. Perceived need and potential applications of a telehospitalist service in rural areas. Telemed $\mathrm{J} E$ Health 2021;27:90-5

19. Sanders RB, Simpson KN, Kazley AS, Giarrizzi GP. New hospital telemedicine services: potential market for a nighttime telehospitalist service. Telemed J E Health. 2014;20:902-8.
20. Gutierrez J, Kuperman E, Kaboli P. Using telehealth as a tool for rural hospitals in the COVID-19 pandemic response. J Rural Health. 2021;37:161-4

21. Sitammagari K, Murphy S, Kowalkowski M, Chou SH, Sullivan M, Taylor S, et al. Insights from rapid deployment of a "Virtual Hospital" as standard care during the COVID-19 pandemic. Ann Intern Med. 2021;174:192-9.

22. Mastrianni D, Felivena R, Brooks T, McDermott B, Tan J, Vandell R, et al Pooled testing for SARS-CoV-2 in hospitalized patients. J Hosp Med. 2020;15:538-9.

23. Auerbach A, O'Leary K, Greysen S, Harrison JD, Kripalani S, Ruhnke GW, et al. Hospital ward adaption during the Covid-19 pandemic: a national survey of academic medical centers. J Hosp Med. 2020;15:583-8.

24. Horwitz L, Jones S, Cerfolio R, Francois F, Greco J, Rudy B, et al. Trends in COVID-19 risk-adjusted mortality rates. J Hosp Med. 2021;16:90-2.

25. Nemer D, Wilner B, Burkle A, Aguilera J, Adewumi J, Gillombardo C, et al. Clinical characteristics and outcomes of non-ICU hospitalization for Covid-19 in a nonepicenter, centrally-monitored healthcare system. J Hosp Med. 2021:16:7-14.

26. Keller M, Kitsis E, Arora S, Chen JT, Agarwal S, Ross MJ, et al. Effect of systemic glucocorticoids on mortality or mechanical ventilation in patients with Covid-19. J Hosp Med. 2020;15:489-93.

27. Cui Z, Merritt Z, Assa A, Mustehsan H, Chung E, Liu S, et al. Early and significant reduction in C-reactive protein levels after corticosteroid therapy is associated with reduced mortality in patients with COVID-19. J Hosp Med. 2021;16:142-8.

28. Soares W III, Schoenfeld E, Visintainer P, Elia T, Medarametla V, Schoenfeld DA, et al. Safety assessment of a noninvasive respiratory protocol for adults with Covid-19. J Hosp Med. 2020:15:734-8.

29. Kisuule F, Howell E. Hospitalists and their impact on quality, patient safety, and satisfaction. Obstet Gynecol Clin North Am. 2015;42:433-46. 